\title{
Das Ökologieproblem und die ökonomische Theorıe
}

\author{
von Frank Beckenbach / Bonn
}

1. Von dem im politischen Kontext üblichen Bezug auf ein normatives Ökologieproblem is't ein analytisches Ökologieproblem zu unterscheiden. Für die Wirtschaftswissenschaften ergibt sich dieses analytische Ökologieproblem daraus, daß die Formen des Wirtschaftens keinen geschlossenen Kreislauf begründen. Als Rohstoff- und Raumkonsument ebenso wie als Produzent von „Exkrementen“ ist die Wirtschaft auf Bedingungen verwiesen, die sie nicht selbst produzieren kann und die natürlicherseits gegeben sein müssen. Darüber hinaus ist die Arbeitskraft ein unentbehrliches Element des Wirtschaftens. Auch für die Reproduktion der Arbeitsfähigkeit kann die Wirtschaft nur Bedingungen setzen, diese aber nicht garantieren. Die gemeinschaftlichen $\mathrm{Na}$ turbedingungen des Wirtschaftens sind nicht selber den Steuerungsleistungen des ökonomischen Kalküls, dem monetären Selbsterhaltungs- und Vermehrungsgebot unterworfen. Dies wird dann zum Problem, wenn die ökonomisch gesteuerte Inanspruchnahme der Naturbedingungen deren Reproduktion gefährdet oder verunmöglicht. In der Sprache der Ökonomie wird dies als gesellschaftliche Folgekosten und als Problem ihrer Verteilung ausgedrückt.

2. Für eine angemessene Behandlung des Ökologieproblems in der Wirtschaftswissenschaft können folgende Anforderungen formuliert werden:

a) Es ist auf eine Betrachtungsweise zu verzichten, die die Lernfähigkeit des sozialen Systems in die Rahmendaten des Modells verweist. Dies bedeutet den Verzicht auf das bis heute in der Wirtschaftswissenschaft vorherrschende mechanische Leitbild (einfache und umkehrbare Kausalitätsbeziehungen, restlose und eindeutige Quantifizierbarkeit der Systemelemente, Zusammensetzbarkeit des Ganzen aus seinen Teilen usw.). Jenseits der Vision eines sich selbstregulierend herstellenden Optimalzustandes (Gleichgewichtsorientierung) einerseits und der Vision einer systemnotwendigen Zusammenbruchstendenz (Krisenorientierung) andererseits geht es um die Formulierung eines lernfähigen ökonomischen Regelsystems zur Verarbeitung von Ungleichgewichten.

b) Es geht um die Verknüpfung von ökonomischen Aggregaten mit sozialen Handlungspotentialen. Es geht darum, wie spezifische soziale Lebensformen spezifische Produktionsund Konsummuster hervorbringen. Bezogen auf die Reichweite der gegenwärtigen Wirtschaftswissenschaft bedeutet dies ihre Erweiterung auf „vorökonomische“ Bedingungen (z.B. Naturkonsum), auf "nachökonomische“ Bedingungen (z.B. häusliche Reproduktion) und ihre Vertiefung auf die in die ökonomischen Kategorien eingeschlossenen sozialen Bedingungen.

t) $\mathrm{Zu}$ berücksichtigen ist schließlich das zunehmende Auseinanderentwickeln von einzelund gesamtwirtschaftlicher Logik. Dies schließt die Überwindung einer Sichtweise ein, in der die gesamtgesellschaftliche Effizienz allein durch Aggregierung einzelwirtschaftlicher Effizienz bestimmt wird.

3. Unzureichendes Problembewußtsein und mangelhafte Problembearbeitung in der Wirtschaftswissenschaft werden nun zum Anlaß genommen, ebendort ein neues ökologisches $\mathrm{Pa}$ radigma auszurufen. In der einen Variante geht es um eine kulturelle Erweiterung der Ökonomie. Die mit der ökologischen Zerstörung in Zusammenhang gebrachte Geldsteuerung soll durch Stärkung von kulturellen Elementen wie Beruf, Familie, Moral und last but not least Vernunft durchbrochen werden. In der anderen Variante geht es um eine Neubestimmung des Verhältnisses von ökonomischer Wertbildung und Natur. Durch Erhebung der Natur zu einem wertbildenden Element soll dem Tauschwertkalkül die Rücksichtnahme auf die natürliche Physis aufgezwungen werden. Weder die Aufwertung traditioneller gesellschaftlicher Steuerungsmedien noch eine rein normative Erhebung der Natur zu einer ökonomischen Kategorie lassen aber eine Sensibilisierung der Geldsteuerung gegenüber den Naturgrundlagen bzw. überhaupt eine Relativierung der Geldsteuerung erwarten. Statt eines neuen Paradigmas ist eine gründliche Abarbeitung an den verschiedenen Schulen der ökonomischen Theorie angesagt.

4. Für eine ökologische Komplettierung der Geldsteuerung scheint die neoklassische Theorie ein geeigneter gedanklicher Referenzpunkt zu sein: hier wird der Preis im allgemeinen daraus erklärt, da $\beta$ ein Gut in einer geringeren Menge zur Verfügung steht, als es von den Individuen gewünscht wird. In dieser Sichtweise löst sich infolgedessen das Ökologieproblem in das Knappwerden von unzerstörten Naturelementen auf. Dies macht es möglich und nötig, sie mit einem Preis zu vesehen, um so auch für diese Güter eine effiziente Allokation zu ermöglichen. Unbestritten ist, daß es für eine derartige preisförmige Allokation der Umweltgüter Grenzen gibt: Erfassung der durch die Umweltnutzung entstehenden Aufwendungen wie auch deren Zuweisung zu einzelnen Wirtschaftssubjekten sind teilweise nicht über eine Preisbildung möglich; die intendierte Neugestaltung der relativen Preise ist in Anbetracht der Vielzahl der Parameter für das Verhalten der Wirtschaftssub- jekte (bes. der Unternehmer) unzulänglich und in Anbetracht gesamtwirtschaftlicher Verflechtungsstrukturen unbestimmt. Die Beschränkung liegt aber auch in der Behandlung des Ökologieproblems als einem bloßen Allokationsproblem. Wie die Reproduktion der Naturgrundlagen sichergestellt werden kann, wird so nicht beantwortet.

5. Eine über den Allokationsaspekt hinausgehende Behandlung des Ökologieproblems scheint nun innerhalb der klassischen Theorietradition (einschließlich ihrer Marxschen Sonderform) möglich zu sein. Gegenüber der in dieser Tradition gepflegten „Unschuld“ des Mengengerüstes (oder marxistisch: der Produktivkräfte) bedarf es dazu eines Rückgangs $\mathrm{zu}$ den gesellschaftlichen Grundlagen des Tauschs und der Preisbildung. Arbeit als private Form des Produzierens einerseits und Teilung der Arbeit andererseits können als Ausgangspunkt für eine Antinomie von einzelund gesamtwirtschaftlicher Logik gelesen werden. Das Auseinanderfallen von Gebrauchswert und Tauschwert sind dann der Schlüssel für die Erklärung der Zerstörung der Naturgrundlagen (Arbeit, Boden). In dieser Sichtweise ist das Ökologieproblem das Ergebnis des Versuchs, die Schranken zu überwinden, die der Kapitalakkumulation durch nicht beliebig vermehrbare Naturelemente gesetzt werden. Deren private Aneignung wird ebenso zu einem Tribut für die Gesellschaft (Grundrente) wie der Versuch, diese Schranken durch Mechanisierung, Chemisierung und Agglomeration hinauszuschieben.

6. Die tendenzielle Gefährdung der Naturgrundlagen macht aus ihnen ein öffentliches Gut. Daraus folgt, daß es für die Naturvernutzung durch die Wirtschaftssubjekte einer politischen Regelung bedarf und die Markt- und Geldsteuerung hier auf strukturelle Grenzen stößt. Als ein Medium zur (dezentralen) Reduktion von Komplexität und als ein Medium zur individuellen Motivierung bleibt aber die Geldsteuerung (vorläufig) unerläßlich. Daraus folgt, daß unter diesen Bedingungen eine Ökologisierung des Wirtschaftens nur über eine Beschränkung und Komplettierung der Geldsteuerung erfolgen kann. Neben eine politisch induzierte Neuordnung der relativen Preise muß die selektive politisch gesetzte Mengenrationierung treten. Mit der Bearbeitung des Ökologieproblems ist also eine Aufwertung der politisch-administrativen Steuerungskomponente verbunden. Deren Erörterung erfordert ein Hinausgehen über die ökonomische Theorie, in der sie eigentlich einen Fremdkörper darstellt. 
(c) 20Io Authors; licensee IÖW and oekom verlag. This is an article distributed under the terms of the Creative Commons Attribution Non-Commercial No Derivates License (http://creativecommons.org/licenses/by-nc-nd/3.o/), which permits unrestricted use, distribution, and reproduction in any medium, provided the original work is properly cited. 